\title{
Chronic spinal muscular atrophy of facioscapulohumeral type
}

\author{
TETSUO FURUKAWA* and YASUO TOYOKURA \\ From the Department of Neurology, University of Tokyo, Tokyo, fapan
}

\begin{abstract}
Summary. Chronic spinal muscular atrophy of FSH type affecting a mother and her son and daughter is reported. The relevant literature is reviewed and the relation between this condition and Kugelberg-Welander (K-W) disease is discussed. Chronic spinal muscular atrophy of FSH type is considered to be a different entity from the eponymous $\mathrm{K}-\mathrm{W}$ disease. Each type of muscular dystrophy, e.g. limb-girdle, FSH, distal, ocular, or oculopharyngeal type, has its counterpart of nuclear origin. A classification of the chronic spinal muscular atrophies is suggested following the classification of muscular dystrophy.
\end{abstract}

Chronic spinal muscular atrophies can be defined as a group of chronic disorders, in which the primary defect is degeneration of the anterior horn cells of the spinal cord and sometimes of the bulbar motor nuclei, but with no evidence of peripheral nerve or pyramidal tract involvement.

Since the reports of Wohlfart, Fex, and Eliasson (1955) and Kugelberg and Welander (1956) on chronic spinal muscular atrophy simulating muscular dystrophy, interest has been focused on this group of disorders. Several attempts have been made to classify the chronic spinal muscular atrophies (Becker, 1963; Zellweger et al, 1969; Emery, 1971); however, there is still much confusion.

In this communication familial cases of chronic spinal muscular atrophy of facioscapulohumeral (FSH) type are reported. The relevant literature is reviewed and the relation between our cases and Kugelberg-Welander disease (K-W disease) is discussed. The classification of these clinically and genetically heterogeneous disorders will be presented.

\section{Case reports}

Case 1. The proband was a 49-year-old housewife (Fig. 1). From the age of 15 years she suffered from muscular atrophy of shoulders and upper arms. Muscle

\footnotetext{
Received 3 June 1975.

- Correspondence to Dr Tetsuo Furukawa, Department of Neurology, Institute of Brain Research, School of Medicine, University of Tokyo, Hongo, Tokyo, Japan.
}

TABLE

CLASSIFICATION OF CHRONIC SPINAL MUSCULAR ATROPHIES

(1) Limb girdle $=$ Kugelberg-Welander disease (autosomal recessive or dominant, sex-linked recessive)

(2) Facioscapulohumeral (autosomal dominant)

? Scapuloperoneal. (autosomal dominant or ? recessive, (3) Distal sex-linked recessive)

(4) Ocular or oculopharyngeal (autosomal dominant)

twitchings were frequently observed. She was diagnosed as FSH muscular dystrophy in another hospital.

When she visited us in 1973, she had myopathic facies. She could not close her eyes properly. Muscle atrophy was noted not only in her face, but also in the neck, shoulders, and upper arms bilaterally. The tongue was normal. Bilateral winging of the scapulae was remarkable. She could not raise her arms over her shoulders. Muscle power was almost half of normal in proximal muscles of the upper extremities. Deep tendon reflexes were abolished in the upper extremities, but normally preserved in the lower extremities. Pathological reflexes were not elicited. Sensation was intact. The distribution of atrophic muscles was similar to that in FSH muscular dystrophy, but profuse fasciculations of muscles were seen in the shoulder-girdles.

At biopsy of the left deltoid muscle nearly 10 years ago she was diagnosed as FSH muscular dystrophy in another hospital. However, our electromyographic(EMG) studies showed action potentials of high amplitude and 
Fig. 1. Case 1. Proband with muscular atrophy of facioscapulohumeral region and winging of scapulae.
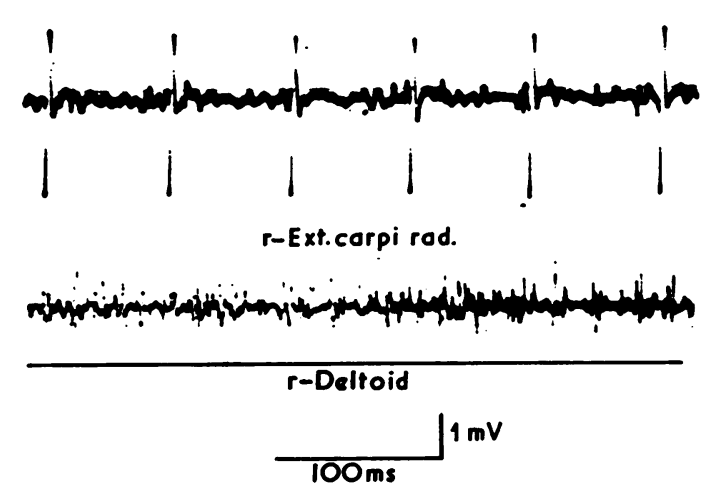

FIG. 2. Action potentials of high amplitude and long duration recorded from extensor carpi radialis muscle of the proband. Myogenic pattern was also observed in deltoid muscle. long duration in various muscles of shoulders and upper extremities as shown in Fig. 2. The so-called myogenic patterns were also seen. Serum creatine kinase (CK) activity was normal. Motor nerve conduction velocities of peripheral nerves were normal. These data were suggestive of the degeneration of the anterior horn cells.

Case 2. A daughter of Case 1 was 21 years old (Fig 3, left). A few years ago she noticed that her face had become thin. Muscles in the neck and shouldergirdles were also atrophic. The muscle atrophy was slightly progressive. Fasciculation of muscles was observed in the shoulder-girdles. EMG showed neurogenic patterns as well as myogenic. Serum CK was normal.

Case 3. A son of the proband (Case 1) was 17 years old (Fig. 3, right). From the age of 10 years he had suffered from muscular atrophy of face, neck, shouldergirdles, and recently of pelvic girdles. At the time of our 


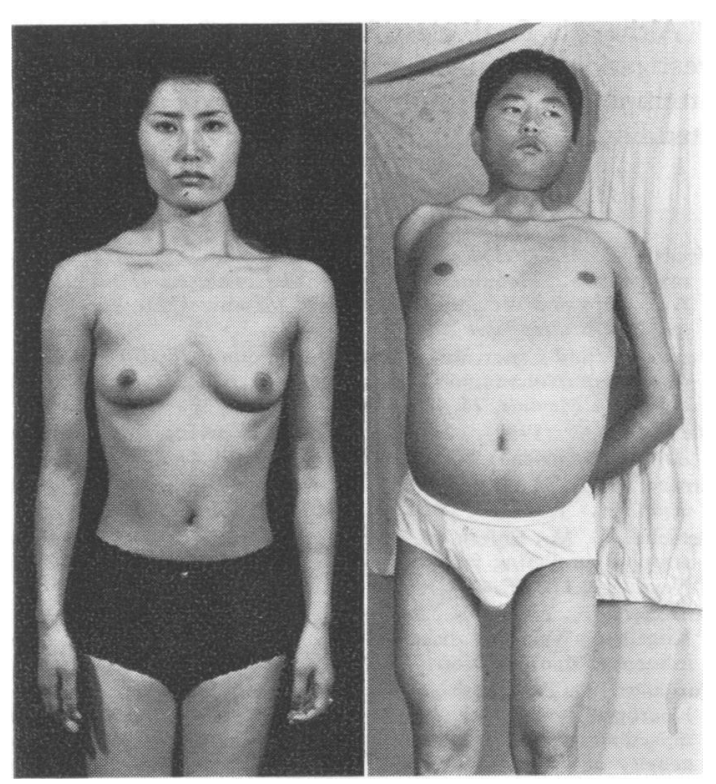

FIG. 3. Left: Case 2, daughter of proband; right: Case 3, son of proband.

examination muscular atrophy was noted in the face, neck, shoulder-girdles, and also in the hips and thighs. Lumber lordosis was accentuated. He could not raise his arms at all, and Gowers's sign was present. He was more severely affected than his mother and sister. Profuse fasciculation of muscles was also seen in this patient. Serum CK was normal. EMG showed the same patterns as in his mother.

The diagnosis was chronic spinal muscular atrophy of FSH type affecting the mother and her son and daughter, probably transmitted by an autosomal dominant gene.

\section{Discussion}

Wohlfart et al (1955) described 'hereditary proximal spinal muscular atrophy' and considered the disorder as an entity simulating progressive muscular dystrophy. In 1956 Kugelberg and Welander published an article entitled 'Heredofamilial juvenile muscular atrophy simulating muscular dystrophy'. Thus, $\mathrm{K}-\mathrm{W}$ disease has been delineated from muscular dystrophy and characterized by spinal muscular atrophy simulating muscular dystrophy, with a slowly progressive course over several decades. However, in all of their cases muscular atrophy simulated the limb girdle type of muscular dystrophy. Though with the increasing number of reports various atypical cases of $\mathrm{K}-\mathrm{W}$ disease have been described, the cardinal feature of the disease resembles limb-girdle type. In this respect, the present cases were different from the eponymous $\mathrm{K}-\mathrm{W}$ disease, because muscular atrophy was of the FSH type. However, histological and electrophysiological findings could not distinguish between the two conditions.

Concerning chronic spinal muscular atrophy of FSH type, Mares et al (1964) reported a family in which 4 members of 2 generations showed the FSH pattern of muscular atrophy, with evidence of both neurogenic and myogenic changes. In 1967 Fenichel, Emery, and Hunt reported the same disorder affecting a mother and her daughter. We reported similar cases as a variant of $K-W$ disease (Furukawa et al, 1969). Recently the same condition was described by some investigators (Patel and Swami, 1969; Igata and Watanabe, 1973; Hosokawa et al, 1974).

A search of the earlier papers shows probable cases of this disorder. In 1885 Landouzy and Dejerine collected many cases of FSH muscular dystrophy, and FSH dystrophy is, therefore, called Landouzy-Dejerine type after their names. In their report, a 25-year-old man was described who had a chronic course and remarkable fasciculation of the muscles. The authors' comment on this case was as follows: 'L'amélioration durant de si longues années, c'est en faveur de la myopathie, mais les contractions fibrillaires des muscles plaident pour la myélopathie (amelioration lasting so many years favours myopathy, but fibrillary contractions of muscles favour myelopathy).' It is worth while noting that Landouzy and Dejerine suggested the presence of this type of chronic spinal muscular atrophy as early as in 1885 . In 1953, Benassi and Canestrari reported an unusual form of muscular dystrophy of Landouzy-Dejerine type. Muscular atrophy was observed in the face and shouldergirdles, with remarkable fasciculation of muscles. Tendon reflexes were abolished and the tongue was slightly atrophic.

These reports suggest that chronic spinal muscular atrophy of FSH type constitutes a distinct entity, which is transmitted as an autosomal dominant trait.

In the present family the male patient was more severely affected than his female sib. This phenomenon, a sex-influenced manifestation, is usually observed in $\mathrm{K}-\mathrm{W}$ disease (Furukawa et al, 1968); however, it must await further accumulation of cases to confirm whether this is also the case with this type of chronic spinal muscular atrophy.

According to the Research Group on Neuromuscular Disorders of the World Federation of Neurology (1968), muscular dystrophy is classified as follows: (1) Duchenne (pseudohypertrophic) 
type. (2) FSH type: ? scapuloperoneal type; (3) limb girdle type; (4) distal myopathy; (5) ocular myopathy; and (6) oculopharyngeal muscular dystrophy. In this classification the eponymous $\mathrm{K}-\mathrm{W}$ disease apparently has a certain resemblance to the limb girdle type, while the present cases resemble the FSH type. Now, it may also be suggested that other types of muscular dystrophy also have their counterparts in a spinal or nuclear origin.

A review of the literature reveals some reports of chronic spinal muscular atrophy simulating distal myopathy (Nelson and Amick, 1966; Meadows and Marsden, 1969; McLeod and Prineas, 1971). Biemond (1955) reported a juvenile form of distal myopathy, which was subsequently found to be neurogenic in origin (Walton and Gardner-Medwin, 1974).

There has been a good deal of controversy on the pathogenesis of ocular or oculopharyngeal muscular atrophy, e.g. dystrophy ? or neuropathy ? This disorder was originally described by Hutchinson (1879) and others as nuclear ophthalmoplegia. However, Kiloh and Nevin (1951) considered the disorder to be a form of muscular dystrophy and introduced the term 'ocular myopathy'. Later, 'oculopharyngeal muscular dystrophy' was described by Victor, Hayes, and Adams (1962). Recently, however, Takahashi et al (1966) and Kuzuhara et al (1974) suggested that some cases of ocular or oculopharyngeal muscular atrophy were of nuclear origin. It is reasonable to consider that there are two kinds of this type of muscular atrophy, e.g. one myopathy and the other nuclear amyotrophy.

It is apparent that each type of muscular dystrophy has its counterpart of spinal or nuclear origin and, as the Duchenne type resembles the limb girdle type in the distribution of atrophic muscles, it could be included in the category of limb girdle type in this discussion.

Therefore the chronic spinal muscular atrophies can be classified as shown in the Table.

The limb girdle type is the eponymous $\mathrm{K}-\mathrm{W}$ disease. The mode of inheritance is autosomal recessive or dominant or rarely sex-linked recessive. The cases described in this paper are FSH in type and this is inherited as an autosomal dominant trait.

Scapuloperoneal muscular atrophy may be dystrophic or spinal (Kaeser, 1965). Spinal scapuloperoneal muscular atrophy may be a variant of FSH type. Others are distal and ocular or oculopharyngeal types. All of them show the same electromyographic and muscle biopsy findings. Therefore, the chronic spinal muscular atrophies may be classified in the same way as those in muscular dystrophy.
Although final classification awaits further in vestigation of underlying metabolic disorders, ard attempt at classification will facilitate the under standing of this group of disorders.

REFBRENCES

Becker, P. E. (1963). Atrophia musculorum spinalis pseudo myopathica. Hereditäre neurogene proximale Amyotrophie vom Kugelberg und Welander. Zeitschrift für menschliche Vererbungs und Konstitutionslehre 37, 193-220.

Benassi, P. and Canestrari, P. (1953). Su una particolare forma di distrofia muscolare tipo Landouzy-Dejerine. Rivista di Patologia Nervosa e Mentale, 74, 435-448.

Biemond, A. (1955). Myopathia distalis juvenilis hereditariacu Acta Psychiatrica et Netrologica Scandinavica, 30, 25-38.

Emery, A. E. H. (1971). The nosology of the spinal musculara atrophies. Fournal of Medical Genetics, 8, 481-495.

Fenichel, G. M., Emery, E. S., and Hunt, P. (1967). Neurogenic atrophy simulating facioscapulohumeral dystrophy. Archives of Neurology, 17, 257-260.

Furukawa, T., Nakao, K., Sugita, H., and Tsukagoshi, H. (1968) Kugelberg-Welander disease. With particular reference to sex $\Theta$ influenced manifestations. Archives of Neurology, 19, 156-162. O

Furukawa, T., Tsukagoshi, H., Sugita, H., and Toyokura, Y. (1969)? Neurogenic muscular atrophy simulating facioscapulohumerat muscular dystrophy. With particular reference to the heterogeneity of Kugelberg-Welander disease. Fournal of the Neurof logical Sciences, 9, 389-397.

Hosokawa, T., Choki, J., Fujishima, H., and Santa, T. (1974). pedigree of neurogenic muscular atrophy with facio-scapulo-s humeral distribution. Clinical Neurology (Tokyo), 14, 660-665. $\bullet$

Hutchinson, J. (1879). An ophthalmoplegia externa or symmetricad immobility (partial) of the eye with ptosis. Transactions of the Medico-Chirurgical Society of Edinburgh, 62, 307.

Igata, A., and Watanabe, S. (1973). Facioscapulohumeral muscular atrophy with neurogenic findings. Fapanese Medical fournal, No. 2557, 47-49.

Kaeser, H. E. (1965). Scapuloperoneal muscular atrophy. Brain 88, 407-418.

Kiloh, L. G. and Nevin, S. (1951). Progressive dystrophy of the external ocular muscles (ocular myopathy). Brain, 74, 115-143.

Kugelberg, E. and Welander, L. (1956). Heredofamilial juvenile muscular atrophy simulating muscular dystrophy. Archives of Neurology and Psychiatry, 75, 500-509.

Kuzuhara, S., Tamaki, M., Mannen, T., and Nakanishi, T. (1974) 'Oculopharyngeal dystrophy' with neurogenic and myogenic changes in skeletal muscles. Clinical Neurology (Tokyo), 14, 206-3 207.

Landouzy, L. and Dejerine, J. (1885, 1886). De la myopathie atrophique progressive. Revue de Médecine, 5, 81-117, 253-366 6, 977-1027.

McLeod, J. G. and Prineas, J. W. (1971). Distal type of chroniő spinal muscular atrophy. Brain, 94, 703-714.

Mares, A., Constantinesco, M., Vasilesco, C., and Ionesco, M.(1964) Atrophie musculaire hérédo-familiale à transmission dominante. Étude clinique, électromyographique et bioptique. Revue Roumaine de Neurologie, 1, 295-307.

Meadows, J. C. and Marsden, C. D. (1969). A distal form of chronic spinal muscular atrophy. Neurology, 19, 53-59.

Nelson, J. W. and Amick, L. D. (1966). Heredofamilial progressiv@ spinal muscular atrophy; a clinical and electromyographic study of a kinship. Neurology, 16, 306.

Patel, A. N. and Swami, R. K. (1969). Muscle percussion and neostigmine test in the clinical evaluation of neuromuscular dis orders. New England Fournal of Medicine, 281, 523-526.

Research Group on Neuromuscular Diseases (1968). Classification of the neuromuscular disorders. Fournal of the Neurologica Sciences, 6, 165-177.

Takahashi, K., Nakamura, H., Wakutani, K., and Nakagawa, $T_{\text {: }}^{+}$ (1966). Descending ocular myopathy associated with neuralo amyotrophy in the extremities. Clinical Neurology (Tokyo), 60 719-725. 
Victor, M., Hayes, R., and Adams, R. D. (1962). Oculopharyngeal muscular dystrophy. New England fournal of Medicine, 267, 1267-1272.

Walton, J. N. and Gardner-Medwin, D. (1974). Progressive muscular dystrophy and the myotonic disorders. In Disorders of Voluntary Muscles, 3rd ed., pp. 561-613. Ed. by J. N. Walton. Churchill Livingstone, Edinburgh and London.
Wohlfart, G., Fex, J., and Eliasson, S. (1955). Hereditary proximal spinal muscular atrophy. A clinical entity simulating muscular dystrophy. Acta Psychiatrica et Neurologica Scandinavica, 30, 395-406.

Zellweger, H., Schneider, H. J., Schuldt, D. R., and Mergner, W. (1969). Heritable spinal muscular atrophies. Helvetica Paediatrica Acta, 24, 92-105. 